\title{
Analisis Penurunan Daya Pada Sistem Propulsi Lokomotif Transmisi Diesel Elektrik CC 203 Di Depo Lokomotif
}

\author{
Denasti Fajar Sidik'; M.Reza Hidayat ${ }^{2}$; Christiono $^{3}$ \\ 1, 2 Jurusan Teknik Elektro, Fakultas Teknik, Universitas Jenderal Achmad Yani, Cimahi, \\ Indonesia. \\ ${ }^{3}$ Sekolah Tinggi Teknik PLN, Jakarta, Indonesia. \\ 1 denastifajar@rocketmail.com \\ ${ }^{2}$ mreza@lecture.unjani.ac.id
}

\begin{abstract}
Research was carried out on the CC203 locomotive propulsion system in order to obtain the value of the power reduction in one case of disturbance by comparing the output value against the set standard value. Using mathematical calculation methods from the applicable equations and processing the data. From the results of the study, the cause of the decrease in locomotive power is due to a decrease in the excitation value so that it affects the output value of the Main Generator at each Notch and has an impact on the motor traction power supply also decreases. The Main Generator can only issue a maximum Horse Power at Notch 8 of 1389.96 HP from 1985.31 HP with a decrease of $595 \mathrm{HP}$. The electric motion of the generator exciter has the largest decrease at Notch 7 of 6.02 volts from 30.48 volts to 24.46 volts. Motor traction can only output a maximum terminal power of 985.067 Watt from $1407 \mathrm{KWatt}$. The maximum electromagnetic torque of the Notch 8 motor traction is $2855.48 \mathrm{~N} . \mathrm{m}$ in the series transition and $3070.21 \mathrm{~N} . \mathrm{m}$ in the parallel transition. Losses on a series transition of 36886 Watts and a parallel transition of 9122 Watts.
\end{abstract}

Keywords: Power, Electromotive Force, Locomotive, Propulsion System

\begin{abstract}
ABSTRAK
Penelitian dilakukan dengan analisis pada sistem propulsi lokomotif CC203 sehingga didapat nilai penurunan daya pada satu kasus gangguan dengan cara membandingkan nilai output terhadap nilai standar yang ditetapkan. Menggunakan metode perhitungan matematis dari persamaan yang berlaku dan mengolah data tersebut pada MS. Excell. Dari hasil penelitian, penyebab penurunan daya lokomotif dikarenakan faktor penurunan nilai Eksitasi sehingga mempengaruhi nilai output dari Main Generator di setiap Notch nya dan berdampak pada suplai daya traksi motor juga menurun. Main Generator hanya dapat mengeluarkan HorsePower maksimal pada Notch 8 sebesar 1389,96 HP dari 1985,31 HP dengan penurunan sebesar 595 HP. Gaya Gerak Lisrik Exciter Generator mengalami penurunan terbesar pada Notch 7 sebesar 6,02 Volt dari 30,48 Volt menjadi 24,46 Volt. Traksi motor hanya dapat mengeluarkan daya terminal maksimal sebesar 985,067Watt dari 1407 KWatt. Torsi Elektromagnetik traksi motor maksimal Notch 8 sebesar 2855,48 N.m pada transisi seri dan 3070,21 N.m pada transisi paralel. Losses pada transisi seri sebesar 36886Watt dan transisi paralel sebesar 9122 Watt.
\end{abstract}

Kata kunci: Daya, Gaya Gerak Listrik, Lokomotif, Sistem Propulsi 


\section{PENDAHULUAN}

Depo Lokomotif merupakan Unit Sarana PT.Kereta Api Indonesia yang bertanggung jawab terhadap kehandalan lokomotifnya dalam menjalankan bisnis transportasi kereta api. Pada dasarnya setiap pekerjaan teknis di Depo Lokomotif telah dilaksanakan sesuai prosedur, namun pada kenyaataannya masih terdapat gangguan yang berdampak pada keterlambatan operasional perkeretaapian. Menurut data laporan bulanan Depo Lokomotif yang direkap dari bulan Februari 2019 sampai dengan bulan Februari 2020 terdapat 6 (enam) kasus gangguan tenaga lemah lokomotif berupa penurunan daya yang mengakibatkan andil keterlambatan perjalanan kereta yang cukup signifikan [1].

Dari kejadian tersebut menunjukan bahwa andil keterlambatan perjalanan kereta yang disebabkan oleh penurunan daya pada saat operasional mempunyai dampak yang sangat signifikan. Terkait permasalahan diatas, terdapat beberapa jurnal atau papper yang berkaitan baik secara khusus pada suatu lokomotif maupun secara umum pada komponen penunjang sistem propulsi sebagai berikut : Jurnal yang pertama tentang efektivitas dan efisiensi sistem propulsi pada Kereta Rel Listrik bahwa sistem motor traksi VVVF (Variable Voltage Variable Frequency) lebih efisien dibanding sistem Rheostatic dan DC-Chopper [2]. Jurnal yang ke dua mengenai penelitian tentang rancangan teknologi sistem propulsi untuk kereta semi-cepat Jakarta-Surabaya dengan sistem Diesel Electric Multiple Unit sebagai pilihan yang paling memungkinkan [3]. Penelitian ke tiga tentang simulasi solusi alternatif untuk meningkatkan efisiensi daya pada kereta diesel-elektrik yang dapat menghemat bahan bakar sebesar $10 \%$ dengan sistem Store The Energy Of The Diesel Dynamic Braking And Reduce The Diesel Motor Size [4]. Jurnal ke empat tentang perubahan output tegangan terminal generator dc berdasarkan perubahan nilai arus penguat medan dan putaran generator [5]. Jurnal ke lima penelitian tentang baik Generator maupun Motor DC memiliki karakteristik khas masing-masing yang harus diperhatikan untuk penerapannya dalam keperluan industri atau keperluan lain [6].

Berdasarkan permasalahan diatas mengenai gangguan tenaga lemah atau penurunan daya lokomotif yang dapat menyebabkan keterlambatan jadwal operasional keret api dan menyangkut nama baik serta citra perusahaan, maka diperlukan penelitian mengenai daya pada sistem propulsi lokomotif untuk dapat mengidentifikasi sumber penyebab terjadinya gangguan. Dengan dilakukannya penelitian ini diharapkan dapat menjadi dasar untuk penelitian-penelitian selanjutnya dan juga pengembangan secara teknis perusahaan kedepannya dalam mengantisipasi gangguan serupa sehingga andil keterlambatan kereta api semakin kecil.

\section{METODE/PERANCANGAN PENELITIAN}

\subsection{Metode Penelitian}

Metode penelitian ini diawali dengan identifikasi masalah berupa kasus gangguan operasional kereta berupa penurunan daya pada sistem propulsi lokomotif. Langkah selanjutnya adalah melakukan studi literatur untuk menentukan landasan teori dan referensi yang akan digunakan sebagai penunjang penelitian yang dilakukan. Setelah itu adalah pengumpulan data berupa data primer dan data sekunder. Selanjutnya adalah proses pengolahan dan analisis data sehingga didapat hasil nilai dari penurunan daya yang tejadi dan sumber penyebab nya. 


\subsection{Pengumpulan Data}

Salah satu kasus gangguan operasional transportasi kereta api yang terjadi adalah Lokomotif CC 203 mengalami gangguan tenaga lemah pada tanggal 26 Juni 2019 yang sebelumnya telah dilakukan pemeliharaan 2 tahunan standarisasi nilai parameter Main Generator dan Exciter Generator di Unit Balai Yasa pada tanggal 18 Oktober 2018.

Data primer adalah data yang dicatat dan didokumentasikan sendiri, sedangkan data sekunder adalah data yang diperoleh secara tidak langsung melalui referensi atau sumber dari pihak lain. Dibawah ini merupakan rangkaian ekuivalen sistem transisi lokomotif CC 203:

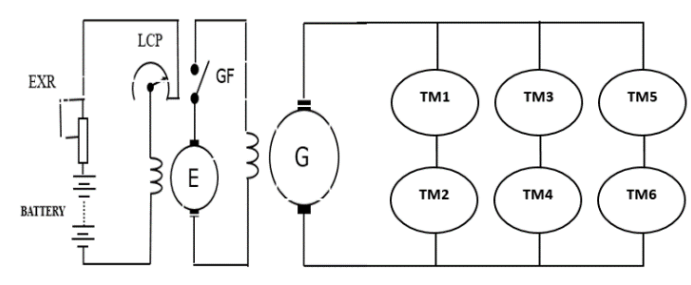

Gambar 1. Sistem Transisi Serie CC203

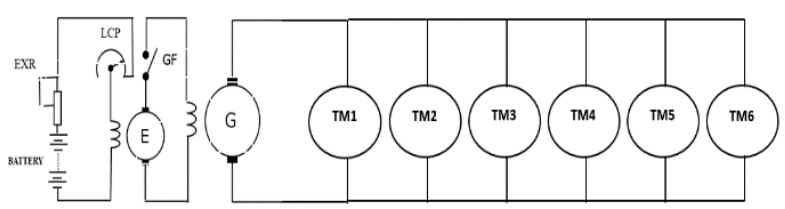

Gambar 2. Sistem Transisi Paralel CC203

Gambar 1 menunjukan sistem propulsi serie yang merupakan kombinasi sambungan secara serie 2 buah traksi motor kemudian menghubungkannya lagi secara paralel dengan traksi motor sambungan serie yang lainnya. Gambar 2 menunjukan hubungan antar traksi motor secara paralel yang akan membuat aliran arus dari generator terbagi menjadi 6 . Proses perpindahan sambungan propulsi dapat dilakukan secara manual maupun secara otomatis menyesuaikan dengan kebutuhan dan kondisi dilintas.

\subsection{Pengolahan Dan Analisis Data}

Proses pengolahan dan analisis data dimulai dari memasukan parameter input yang sebelumnya diperoleh melalui metode pengukuran secara langsung dilapangan, wawancara dan Manual Instruction Books. Pada sistem Eksitasi, parameter input untuk perhitungan yang diperlukan adalah Vbaterai, R.exr, Rf, Ra, dan Rshunt. Pada Main Generator parameter input yang diperlukan adalah besaran nilai Tegangan (VT) dan Arus (I).

Setelah parameter input lengkap, perhitungan dilakukan untuk mencari nilai output Exciter Generator I.BattField, GGL, IL, la, Ishunt. Sedangkan pada Main Generator parameter output yang dicari adalah HP. Untuk Traksi motor dicari nilai daya dan Torsi Elektromagnetiknya.

Tahap selanjutnya dilakukan perbandingan pada nilai standar dan analisis penyimpangan lalu mencari penyebab dari hal tersebut. Untuk lebih memudahkan dalam melihat perbandingan, data diolah dalam Ms. Excell dan digambarkan dalam bentuk grafik. 


\section{HASIL DAN PEMBAHASAN}

\subsection{Perhitungan Nilai Arus Baterry Field}

Persamaan dari arus Battery Field digunakan untuk mencari besarnya arus baterai terhadap kumparan medan Exciter Generator [7].

$$
\text { I.BattField }=\frac{\text { Vbattery }}{\text { R.exr+R.BattField }}
$$

Tabel 1. Perhitungan Nilai Arus Baterai Field (I.BattField)

\begin{tabular}{|c|c|c|c|c|}
\hline Notch & V.Battery $(\mathrm{V})$ & R.Exr $(\mathrm{K} \Omega)$ & $\begin{array}{c}\text { R.BattField } \\
(\Omega)\end{array}$ & $\begin{array}{c}\text { I.BattField } \\
(\mathrm{mA})\end{array}$ \\
\hline 1 & 73 & 343 & 22,5 & 200 \\
\hline 2 & 73 & 186 & 22,5 & 350 \\
\hline 3 & 73 & 165 & 22,5 & 390 \\
\hline 4 & 73 & 133 & 22,5 & 470 \\
\hline 5 & 73 & 103 & 22,5 & 580 \\
\hline 6 & 73 & 93 & 22,5 & 630 \\
\hline 7 & 73 & 80 & 22,5 & 710 \\
\hline 8 & 73 & 67 & 22,5 & 820 \\
\hline
\end{tabular}

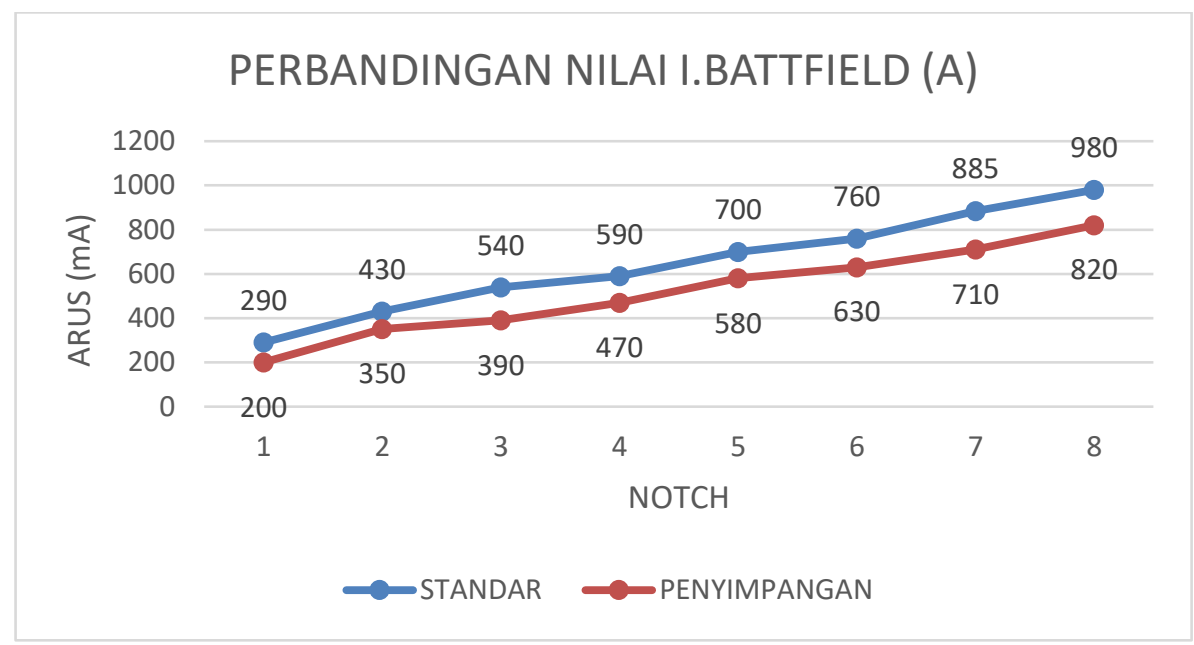

Gambar 3. Grafik Perbandingan Nilai I.BattField

Gambar 3 menunjukan grafik perbandingan nilai standar arus Batery Field dengan kondisi setelah terjadi gangguan. Dari grafik tersebut dapat terlihat bahwa nilai arus Batery Field mengalami penurunan atau penyimpangan dari standarnya. Hal tersebut dipengaruhi oleh perubahan nilai parameter input R.exr. Penurunan terbesar pada kasus tersebut terjadi pada notch 7 sebesar $175 \mathrm{~mA}$ dari $885 \mathrm{~mA}$ menjadi $710 \mathrm{~mA}$. 


\subsection{Perhitungan Nilai IL, IF Shunt, la Dan Vt Exciter Generator}

Tabel 2. Hasil Perhitungan IL, IF Shunt Dan la Exciter Generator

\begin{tabular}{|c|c|c|c|c|c|c|}
\hline Notch & $\mathrm{Vt}=\mathrm{Vf}($ Gen) & $\begin{array}{c}\mathrm{Rf}(\text { Gen.) } \\
\Omega\end{array}$ & $\mathrm{Rf}(\mathrm{Exc}) \Omega$ & $\mathrm{IL}(\mathrm{A})$ & $\mathrm{IF}$. shunt $(\mathrm{A})$ & $\mathrm{IA}(\mathrm{A})$ \\
\hline 1 & 5,75 & 1,755 & 0,45 & 3,28 & 12,78 & 16,06 \\
\hline 2 & 8,47 & 1,755 & 0,45 & 4,82 & 18,81 & 23,63 \\
\hline 3 & 9,39 & 1,755 & 0,45 & 5,35 & 20,86 & 26,21 \\
\hline 4 & 12,69 & 1,755 & 0,45 & 7,23 & 28,20 & 35,43 \\
\hline 5 & 16,07 & 1,755 & 0,45 & 9,16 & 35,72 & 44,88 \\
\hline 6 & 18,59 & 1,755 & 0,45 & 10,59 & 41,32 & 51,91 \\
\hline 7 & 20,55 & 1,755 & 0,45 & 11,71 & 45,68 & 57,39 \\
\hline 8 & 23,77 & 1,755 & 0,45 & 13,55 & 52,83 & 66,37 \\
\hline
\end{tabular}

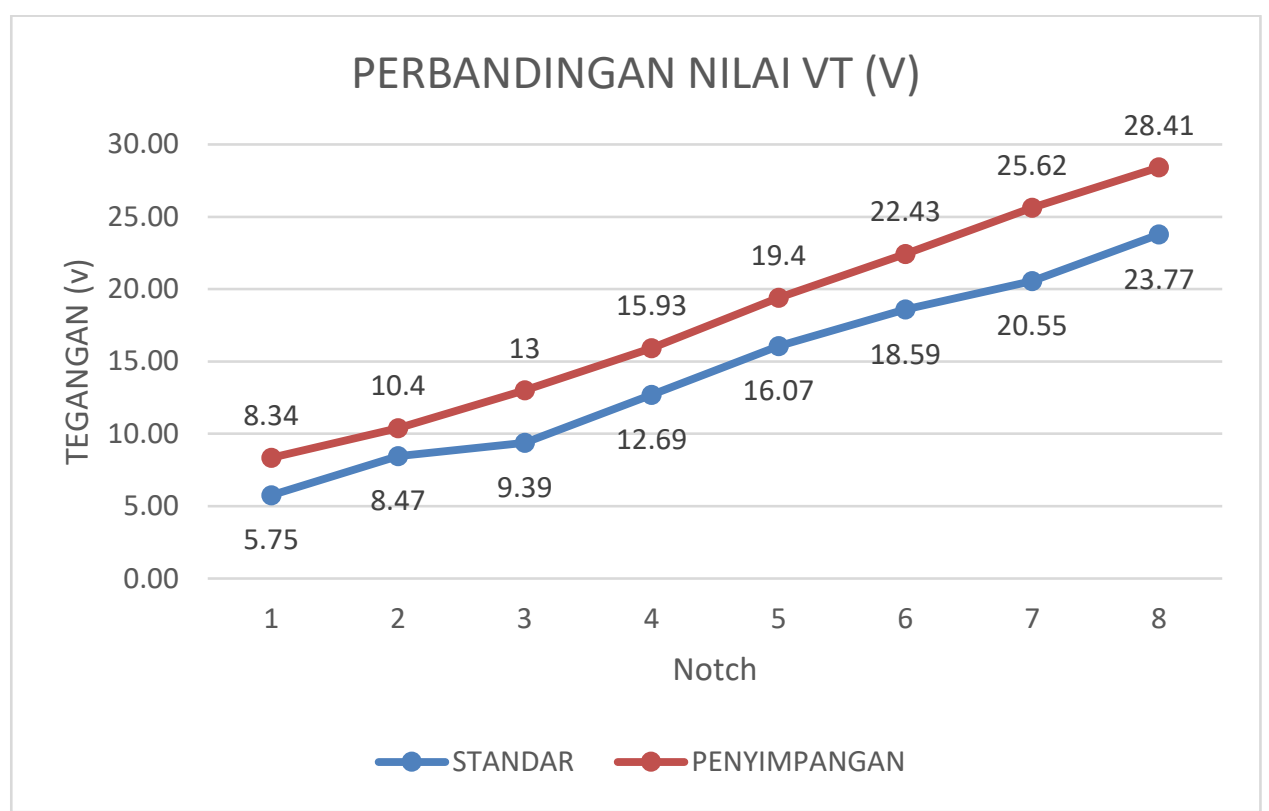

Gambar 4. Perbandingan Nilai Tegangan Terminal (VT) Exciter Generator

Dari grafik tersebut terlihat bahwa nilai VT mengalami penurunan dan menyimpang dari nilai standar pada saat terjadi gangguan. Hal tersebut dikarekan oleh efek penyimpangan nilai parameter arus Battery Field (I.BattField). Penurunan nilai tegangan terminal (VT) terbesar terjadi pada saat notch 7 dimana penurunan nilai tegangan sebesar 5 Volt dari 25,62 Volt menjadi 20,55 Volt.

\subsection{Perhitungan Nilai GGL (Ea) Exciter Generator}

Gaya Gerak Listrik (GGL) akan muncul ketika kumparan jangkar diputar memotong garis gaya medan magnet [8]. Persamaan nilai $\mathrm{GGL}$ adalah $\mathrm{Ea}=\mathrm{Vt}-\mathrm{la}$. Ra 
Tabel 3. Hasil Perhitungan Nilai GGL Exciter Generator

\begin{tabular}{|c|c|c|c|c|}
\hline Notch & $\mathrm{Vt}(\mathrm{Exc})$ & $\mathrm{IA}(\mathrm{A})$ & $\mathrm{Ra}(\Omega)$ & $\mathrm{Ea}(\mathrm{V})$ \\
\hline 1 & 5,75 & 16,06 & 0,003 & 5,80 \\
\hline 2 & 8,47 & 23,63 & 0,003 & 8,54 \\
\hline 3 & 9,39 & 26,21 & 0,003 & 9,47 \\
\hline 4 & 12,69 & 35,43 & 0,003 & 12,80 \\
\hline 5 & 16,07 & 44,88 & 0,003 & 16,21 \\
\hline 6 & 18,59 & 51,91 & 0,003 & 18,75 \\
\hline 7 & 20,55 & 1,755 & 0,003 & 20,73 \\
\hline 8 & 23,77 & 1,755 & 0,003 & 23,97 \\
\hline
\end{tabular}

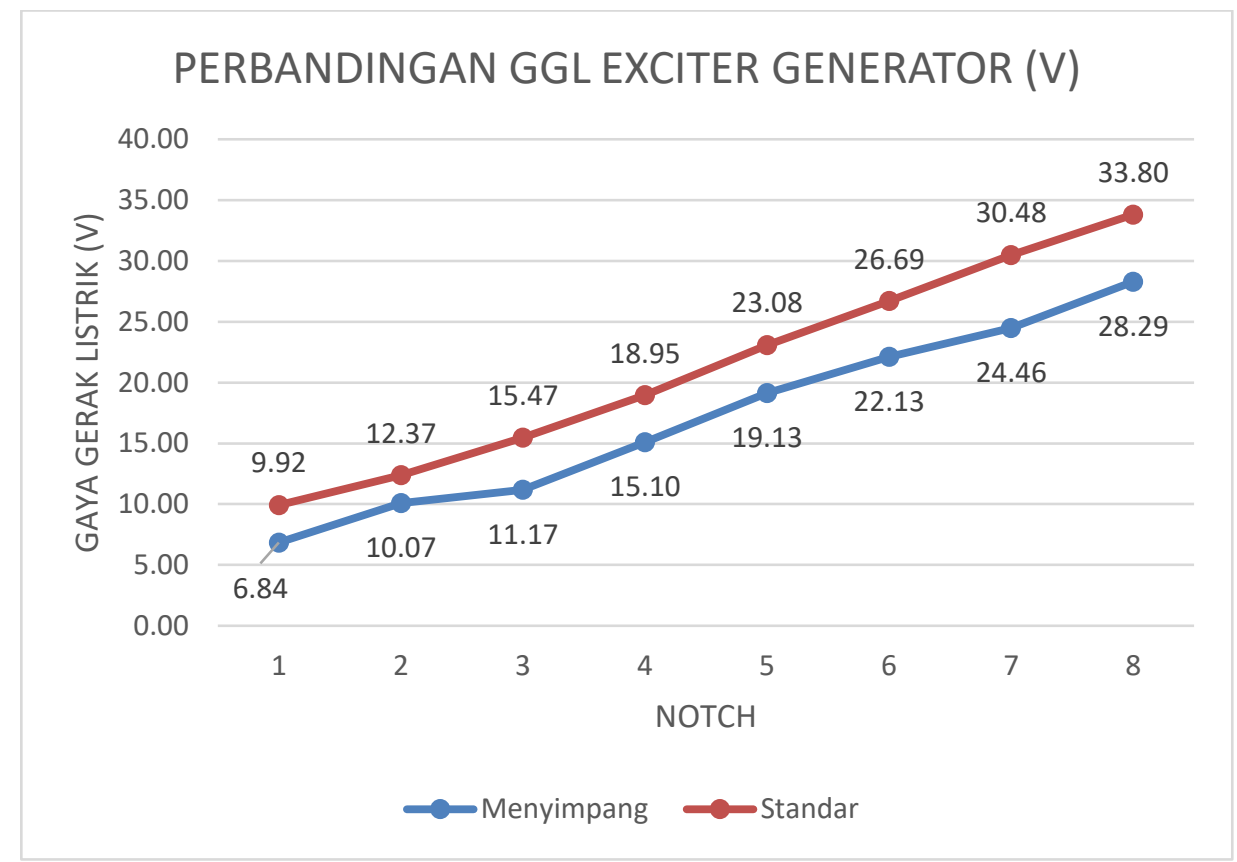

Gambar 5. Perbandingan Nilai GGL (Ea) Exciter Generator

Gambar 5 menunjukan grafik perbandingan nilai GGL (Ea) Exciter Generator standar dengan hasil pengukuran setelah terjadi kasus gangguan. Pada grafik tersebut nilai GGL mengalami penurunan dari nilai standar yang ditetapkan. Penurunan nilai GGL Exciter Generator terjadi pada saat Notch 7 sebesar 6,02 Volt dari 30,48 Volt menjadi 24,46 Volt.

\subsection{Analisis Perhitungan Pada Main Generator}

Horse Power adalah suatu besaran yang digunakan untuk menyatakan besarnya daya yang dihasilkan generator untuk bisa menarik beban lokomotif [9]. Persamaannya adalah :

$$
\mathrm{HP}=\frac{V \times I}{746 \times 0,95}
$$


Tabel 4. Hasil Perhitungan Nilai-Nilai Parameter Pada Generator

\begin{tabular}{|c|c|c|c|c|c|}
\hline NOTCH & VOLT $(\mathrm{V})$ & AMP $(\mathrm{I})$ & RA $(\Omega)$ & EA $(\mathrm{V})$ & HP \\
\hline 1 & 54,48 & 121,38 & 0,003 & 54,847 & 9,331 \\
\hline 2 & 121,28 & 265,35 & 0,003 & 122,075 & 45,409 \\
\hline 3 & 186,33 & 397,22 & 0,003 & 187,525 & 104,439 \\
\hline 4 & 289,17 & 607,81 & 0,003 & 290,993 & 248,005 \\
\hline 5 & 421,74 & 877,46 & 0,003 & 424,375 & 522,169 \\
\hline 6 & 515,61 & 1062,71 & 0,003 & 518,793 & 773,161 \\
\hline 7 & 604,10 & 1229,86 & 0,003 & 607,791 & 1048,347 \\
\hline 8 & 699,51 & 1408,22 & 0,003 & 703,735 & 1389,964 \\
\hline
\end{tabular}

Dari gambar diatas dapat disimpulkan bahwa HP mengalami penurunan nilai dari standar yang ditetapkan. Penurunan nilai tersebut diakibatkan oleh nilai eksitasi yang juga menurun. Penurunan nilai Horse Power terbesar pada Main Generator terjadi pada Notch 8 sebesar 595 HP dari 1985,31 HP menjadi 1389,96 HP.

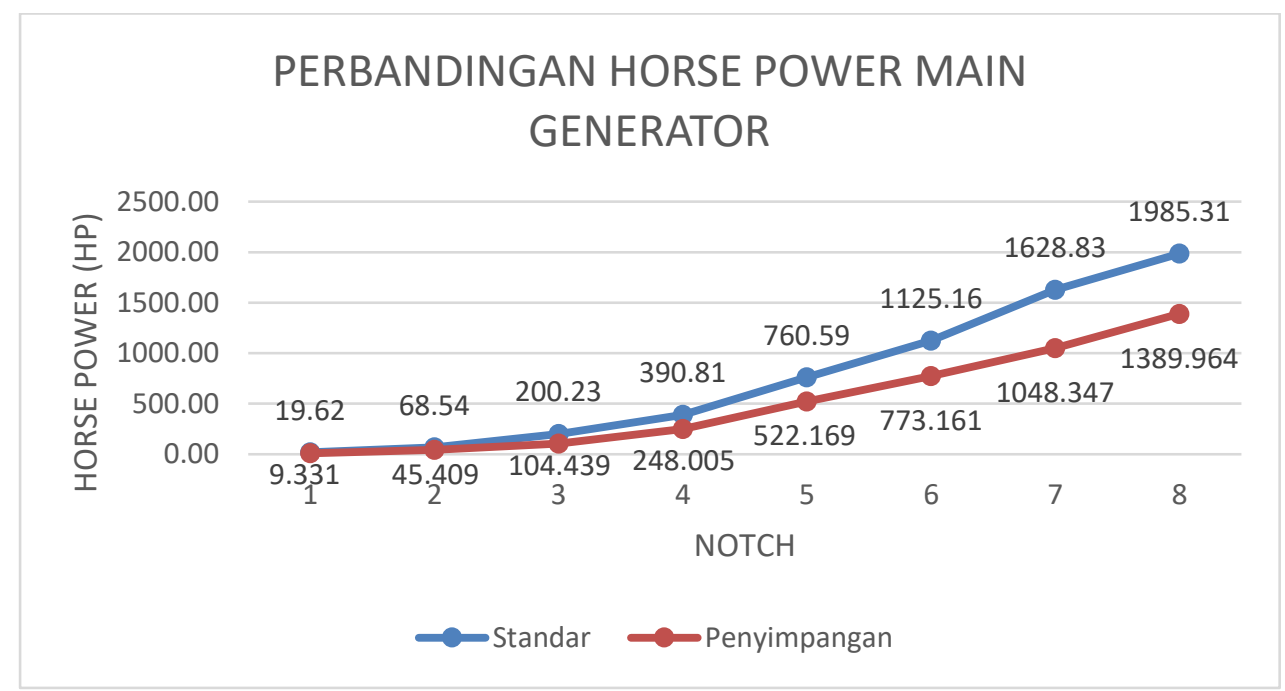

Gambar 6. Grafik Perbandingan Nilai Horse Power Main Generator

\subsection{Analisis Perhitungan Pada Traksi Motor}

Pada traksi motor perhitungan yang dilakukan adalah mencari nilai daya terminal

(P) dan torsi elektromagnetik pada motor secara keseluruhan ( $\left.T_{\text {mech }}\right)$. Torsi elektromagnetik adalah besarnya daya medan magnet untuk menggerakkan rotor [10].

$$
\mathrm{T}_{\text {mech }}=\frac{E a \times I a}{100 \pi}
$$

Perhitungan dilakukan berdasarkan parameter input dari nilai-nilai Main Generator sesuai pada Tabel 6 diatas. Hasil dari perhitungan yang dilakukan adalah sebagai berikut 
Vol. 10, No. 2, Desember 2020, P-ISSN 2356-1505, E-ISSN 2656-9175 https://doi.org/10.33322/sutet.v10i2.1296

Tabel 5. Hasil Perhitungan Nilai Parameter Traksi Motor Transisi Seri

\begin{tabular}{|c|c|c|c|c|c|c|c|c|}
\hline NOTCH & $\begin{array}{c}\text { VOLT } \\
(\mathrm{V})\end{array}$ & AMP $(\mathrm{I})$ & Rs.Total & Ra.Total & EA (V) & $\begin{array}{c}\text { Torsi } \\
(\mathrm{N} . \mathrm{m})\end{array}$ & $\begin{array}{c}\mathrm{P} \\
(\text { Watt })\end{array}$ & $\begin{array}{c}\text { Losses } \\
(\text { Watt })\end{array}$ \\
\hline 1 & 54,48 & 121,38 & 0,026 & 0,0186 & 49,07 & 18,97 & 6613 & 274 \\
\hline 2 & 121,28 & 265,35 & 0,026 & 0,0186 & 109,44 & 92,49 & 32181 & 1310 \\
\hline 3 & 186,33 & 397,22 & 0,026 & 0,0186 & 168,62 & 213,31 & 74016 & 2935 \\
\hline 4 & 289,17 & 607,81 & 0,026 & 0,0186 & 262,06 & 507,27 & 175761 & 6872 \\
\hline 5 & 421,74 & 877,46 & 0,026 & 0,0186 & 382,61 & 1069,18 & 370061 & 14321 \\
\hline 6 & 515,61 & 1062,71 & 0,026 & 0,0186 & 468,21 & 1584,62 & 547939 & 21006 \\
\hline 7 & 604,10 & 1229,86 & 0,026 & 0,0186 & 549,25 & 2151,28 & 742963 & 28134 \\
\hline 8 & 699,51 & 1408,22 & 0,026 & 0,0186 & 636,70 & 2855,48 & 985067 & 36886 \\
\hline
\end{tabular}

Tabel 6. Hasil Perhitungan Nilai Parameter Traksi Motor Transisi Paralel

\begin{tabular}{|c|c|c|c|c|c|c|c|}
\hline NOTCH & $\begin{array}{c}\text { VOLT } \\
(\mathrm{V})\end{array}$ & AMP (I) & Rp.Total & Ra.Total & EA (V) & $\begin{array}{c}\text { Torsi } \\
(\mathrm{N} . \mathrm{m})\end{array}$ & $\begin{array}{c}\text { Losses } \\
(\mathrm{Watt})\end{array}$ \\
\hline 1 & 54,48 & 121,38 & 0,006 & 0,0046 & 53,20 & 20,56 & 68 \\
\hline 2 & 121,28 & 265,35 & 0,006 & 0,0046 & 118,47 & 100,11 & 324 \\
\hline 3 & 186,33 & 397,22 & 0,006 & 0,0046 & 182,12 & 230,39 & 726 \\
\hline 4 & 289,17 & 607,81 & 0,006 & 0,0046 & 282,73 & 547,28 & 1699 \\
\hline 5 & 421,74 & 877,46 & 0,006 & 0,0046 & 412,44 & 1152,55 & 3542 \\
\hline 6 & 515,61 & 1062,71 & 0,006 & 0,0046 & 504,34 & 1706,90 & 5195 \\
\hline 7 & 604,10 & 1229,86 & 0,006 & 0,0046 & 591,07 & 2315,06 & 6958 \\
\hline 8 & 699,51 & 1408,22 & 0,006 & 0,0046 & 684,58 & 3070,21 & 9122 \\
\hline
\end{tabular}

Tabel 5 dan 6 merupakan hasil dari perhitungan nilai traksi motor dengan sistem transisi seri dan paralel. Dengan sistem transisi paralel menghasilkan nilai output dari GGL (Ea) dan Torsi Elekromagnetik lebih besar dibandingkan sistem transisi serie. Dalam hasil perhitungan faktor Losses kumparan Armature pada sistem transisi paralel lebih kecil dibandingkan dengan serie, semakin kecil nilai Losses maka akan semakin baik efisiensi yang dihasilkan.

\section{KESIMPULAN DAN SARAN}

Dari hasil penelitian ini dapat diambil kesimpulan bahwa semua parameter output pada Exciter Generator dan Main Generator mengalami penurunan nilai pada setiap Notch nya sehingga membuat tenaga lemah lokomotif. Penyebab dari hal tersebut adalah menurunnya nilai Eksitasi sehingga membuat nilai output dari Main Generator menjadi menurun dan juga berimbas pada suplai daya traksi motor. Seperti pada Gambar 6, Main Generator hanya dapat mengeluarkan Horse Power maksimal pada Notch 8 sebesar 1389,96 HP dari yang seharusnya sebesar 1985,31 HP dengan penurunan nilai sebesar 595 HP. Perubahan nilai tahanan Variable Resistor R.exr mengakibatkan suplai arus baterai terhadap kumparan Field Exciter Generator tidak maksimal sehingga mempengaruhi nilai GGL Exciter Generator seperti pada Gambar 5 dimana GGL mengalami penurunan terbesar pada saat Notch 7 sebesar 6,02 Volt dari 30,48 Volt menjadi 24,46 Volt. 
Penurunan nilai GGL Exciter Generator mempengaruhi nilai tegangan terminalnya (Vt) seperti pada Gambar 4 dimana penurunan nilai tegangan terminal (VT) terbesar terjadi pada saat notch 7 sebesar 5 Volt dari 25,62 Volt menjadi 20,55 Volt. Perubahan nilai output Main Generator berimbas pada traksi motor yang hanya dapat mengeluarkan daya terminal sebesar 985,067Watt dari daya sebesar $1407 \mathrm{KWatt}$. Torsi Elektromagnetik maksimal pada Notch 8 sebesar 2855,48 N.m pada traksi motor transisi seri dan 3070,21 N.m pada traksi motor transisi paralel. Nilai Losses jangkar pada sistem transisi seri lebih besar dibandingkan transisi paralel,. Losses pada saat transisi seri sebesar 36886Watt dan transisi paralel sebesar 9122 Watt.

\section{UCAPAN TERIMAKASIH}

Penulis mengucapkan terima kasih kepada perusahaan yang telah memberi dukungan dan membantu pelaksanaan penelitian ini dan juga kepada semua pihak yang telah terlibat sehingga dapat terselesaikannya penelitian ini. Semoga Allah SWT membalas setiap kebaikan dengan kebaikan yang berlebih. Aamiin

\section{DAFTAR PUSTAKA}

[1] Depo Lokomotif Bandung, "LAPORAN BULANAN," 2020.

[2] U. Y. Prakoso and M. Sadikin, "Sistem Propulsi Pada Kereta Rel Listrik Di Depo Krl Depok," 2013.

[3] L. Shalahuddin, K. E. Putranto, and D. B. Eskayudha, "Propulsion System Design For The Indonesian Semi High Speed Train" 2019.

[4] E. Agenjos et al., "Energy efficiency in railways: Energy storage and electric generation in diesel electric locomotives," IET Conf. Publ., no. 550 CP, 2009, doi: 10.1049/cp.2009.0734.

[5] J. T. Elektro and P. N. Padang, "Analisis Penentuan Tegangan Terminal Pada Generator DC Penguat Terpisah Untuk Beban Variabel Menggunakan Kurva Saturasi Tanpa Beban Defining of Output Voltage at Load Variable Separately Field Direct Current Generator Using No-load Curve Analysis," Poli Rekayasa, vol. 8, no. April, pp. 40-46, 2013.

[6] S. Muttaqin, "Analisa Karakteristik Generator dan Motor DC," no. 21060112130034, pp. 1-11, 2013.

[7] A. E. Fitzgerald, C. Kingsley, and S. D. Umans, Electric Machinery Fundamentals 6th ed, 6th ed. New York: McGraw-Hill, 2003.

[8] S. J. Chapman, Electric Machinery Fundamentals, 4th ed. New York: McGraw-Hill, 2005.

[9] M. Maruchan, "Sistem Elektrik Lokomotif," Bandung: Pusat Pendidikan Dan Pelatihan Ir.H.Djuanda PT.KAI, 2016.

[10] H. Sutrisno, Suryono, and P. H. Hastungkoro, Motor Listrik Arus Searah. Klaten: Saka Mitra Kompetensi, 2011. 